Douglas Perreira, Jamille Lanutti, Luis Carlos Paschoarelli, Olympio Pinheiro *

\title{
Comparação de técnicas de prototipagem tradicional manual e sua importância para 0 design
}

Douglas Daniel Pereira

Doutorando; UNESP

<dougdanielpereira@gmail.com>

Jamille Noretza de Lima Lanutti

Doutoranda; UNESP

<jamille_lanutti@hotmail.com>

Luis Carlos Paschoarelli

Professor Livre Docente; UNESP <paschoarelli@faac.unesp.br>

Olympio José Pinheiro

Professor Doutor; UNESP

<holihn@uol.com.br>
Resumo O Design é uma atividade muito ampla, que consiste em criar produtos, objetos que em seguida serão fabricados e comercializados. Dentro desse processo de criação existe uma etapa imprescindível que é a utilização de modelos e protótipos, que podem ser confeccionados nos mais diferentes tipos de técnicas e materiais. Assim esse trabalho tem como objetivo comparar diversas técnicas de prototipagem tradicional executadas manualmente, utilizando e classificando variadas técnicas e materiais, levando em consideração critérios como Custo, Tempo de execução e Nível de dificuldade, elegendo para isso um produto (embalagem) que servirá de exemplo a fim de gerar comparações entre os modelos desenvolvidos.

Palavras chave Design, Modelagem, Modelos, Protótipos.

\section{Comparison of traditional manual prototyping techniques and their importance} to design

Abstract Design is a very broad activity, which consists of creating products, objects that then will be manufactured and marketed. In this setting process there is a step that is essential to use models and prototypes can be made in many different kinds of techniques and materials. Thus, this study aims to compare the various traditional prototyping techniques performed manually, using and classifying the various techniques and materials, taking into account criteria such as cost, implementation time and level of difficulty, choosing for this a product (packaging) that serve as an example to generate comparisons between the developed models.

Keywords Design, Modeling, Models, Prototyping. 


\section{INTRODUÇÃO}

O Design é um elemento fundamental no desenvolvimento de produtos e sistemas e deve sempre buscar durante o desenvolvimento de projetos ferramentas, técnicas e materiais que o auxiliem na busca por Inovação.

Para isso, durante o processo, o designer faz uso de modelos e protótipos que nada mais são do que a materialização de ideias que o auxiliam durante o projeto, pois os protótipos permitem a interação não só com a equipe de projeto, mas também com o usuário. Isso faz com que menos erros sejam cometidos ao longo do processo de desenvolvimento, pois ao construir um modelo o designer tem a possibilidade de testar aquela ideia ou forma e corrigir qualquer eventual erro em qualquer fase do projeto.

Para a construção desses modelos e protótipos os designers fazem uso de diversos materiais que facilitam e auxiliam a materialização de suas ideias. Materiais esses que vão desde os mais simples e rudimentares, como papéis e cola, até os mais atuais e sofisticados.

Assim a comunicação entre o Design e as outras áreas do conhecimento, associadas a esses materiais e tecnologias, se transformam em uma estratégia poderosa para $o$ desenvolvimento de produtos e sistemas.

Logo, o conhecimento dos diferentes tipos de modelos e de sua produção é de grande relevância ao Design. Desta forma, este trabalho tem como objetivo comparar as diversas técnicas de prototipagem tradicional executadas manualmente, levando em consideração critérios como Custo, Tempo de execução e Nível de dificuldade, afim e gerar reflexão.

\section{REFERENCIAL TEÓRICO}

\subsection{Conceito de Design}

O Design é considerado um fenômeno do século XX, que surgiu progressivamente com os primórdios da Revolução Industrial, a qual despontou as funções de criação, produção e venda. Antes a fabricação era concentrada apenas em modelos artesanais, mas com as mudanças históricas, políticas, econômicas, sociais e o rápido progresso da tecnologia, a evolução das funções dos produtos - que antes era ligada a descobertas em uma produção unitária ou em pequenas séries - deu início a uma tentativa de unir arte e indústria (CARDOSO, 2008).

Segundo Relvas (2002) o termo design deve ser entendido como o processo e o seu resultado, é muitas vezes descrito, como o processo de transformar as ideias em coisas materiais.

O sucesso do design é substancialmente suportado pela capacidade de permitir que o fabricante diferencie seu produto para além da tecnologia, criando além de formas inovadoras um produto que satisfaça o seu usuário em todos os sentidos.

A atividade do designer está ligada ao desenvolvimento de um produto e sua respectiva produção com o intuito de criar produtos que sigam e preconizem novos estilos, integrem novas tecnologias, promovam a evolução e a criação de novos mercados. O design também se constitui como parte integrante e inseparável da inovação e pode contribuir para o aumento da inovação e o progresso, diversificação da inovação e a modernização e remodelação, inovação radical e as novas capacidades e produtos (RELVAS 2002).

Assim é visível a importância do design no desenvolvimento de novos produtos e tecnologias, bem como para contribuir de maneira significativa para a melhoria de projetos já existente, pois o mesmo associado às técnicas de prototipagem que auxiliam na descoberta de possíveis problemas, colaborando para o desenvolvimento de produtos que atendam às necessidades dos usuários.

\subsection{Protótipos e sua importância}

O termo protótipo possui diferentes significados e em design permite o uso de diversas nomenclaturas, dependendo da área e da etapa do desenvolvimento do projeto. Podendo partir de um simples modelo com materiais comuns, até a configuração do produto em sua escala real com o mesmo material, acabamento e funcionalidade. 
O termo protótipo, que vem do grego prototypus (proto = primeiro, typus = tipo), ou seja, é o primeiro do seu tipo em representações de uma peça ou produto.

Segundo Baxter (1998), no processo de design de produtos, a palavra protótipo se refere a dois tipos de representação: (1) no sentido mais preciso, refere-se à representação física do produto que será produzido industrialmente, (2) no sentido mais lato, refere-se a qualquer tipo de representação física construída com o objetivo de realizar testes físicos.

Alcoforado (2014) afirma que genericamente diversos autores em todo o mundo se dirigem as etapas de representação das características físicas de um produto ou sistema através do termo prototipagem, dividindo-os de acordo com o nível de fidelidade (baixa, média e alta fidelidade).

Segundo Chrissis et al. (2003) o protótipo seria um tipo preliminar do aspecto físico ou funcional do produto, servindo como modelo tanto para as fases posteriores do projeto - onde há a necessidade de testar funcionalidade - quanto para as fases iniciais auxiliando e corrigindo qualquer eventualidade do produto.

Segundo Ulrich e Eppinger (1995) o protótipo é definido como uma aproximação do produto ao longo de uma ou mais dimensões de interesse. Baseado nesta definição, um protótipo pode ser visto como uma entidade que exibe algum aspecto do produto de interesse do pessoal de desenvolvimento.

Por sua vez Santos (1999 apud VOLPATO et al. 2007) define protótipo como qualquer modelo tridimensional físico de uma peça, componente, mecanismo ou produto que se realiza antes da sua industrialização, com a finalidade de validar todas ou algumas de suas características estabelecidas no projeto. Os requisitos impostos aos protótipos com relação à estabilidade mecânica (resistência, elasticidade, dureza, etc.), térmica e química do componente estão limitados àqueles necessários para o propósito de teste funcional.

Martins (2010) afirma que os protótipos podem ser utilizados para representar um produto por completo ou até uma peça ou um componente isolado, e é uma ferramenta fundamental no desenvolvimento de um projeto ou produto, pois os modelos tridimensionais físicos são meios de representação utilizados em várias fases do desenvolvimento do produto, não só como auxiliares, mas como peças fundamentais na concepção de artefatos tridimensionais.

A utilização de protótipos nas etapas de desenvolvimento de um produto pode ser complementada com outros meios de avaliação, contribuindo para o estudo e a definição dos aspectos físicos e funcionais do produto a ser desenvolvido.

Segundo Santos (2006), o uso de modelos tridimensionais nos projetos se intensificou a partir de 1960 em estudos de simulação nas áreas da aviação e estudos espaciais, assim como na indústria automobilística.

Para Martins (2010) esses modelos são elementos importantes na tradução de informação bidimensional para um formato que permite ao designer outra compreensão da relação entre os vários componentes e a forma do novo produto.

De acordo com Forti (2005) conforme as ideias e conceitos amadurecem em um projeto, a necessidade de avaliá-lo de uma forma mais confiável se torna necessária e os modelos tridimensionais trazem aos espectadores uma visão mais próxima do que será o produto final. Não sendo necessário imaginar a forma volumétrica do conceito.

Martins (2010) afirma que na fase conceitual, os designers não ambicionam representações do produto final, utilizando modelos para demonstrar ideias, conceitos e eventualmente a sugestão do seu funcionamento. Através deles, poderão descobrir áreas que necessitam ser melhoradas e realizar mudanças inesperadas de falhas que não foram detectadas na idealização ou nos estudos bidimensionais realizados. 
Junto a isso é adicionado à utilização de representações físicas do produto (tais como maquete, modelo, mock-up, protótipo) que são essenciais no processo de entendimento rápido dos requisitos do produto por todos os envolvidos em cada etapa de seu desenvolvimento (VOLPATO et al., 2007).

Assim, pode-se dizer que, o uso de modelos é de grande importância para a práxis do Design durante as várias etapas metodológicas de desenvolvimento de produto.

\subsection{Modelagem tradicional manual e Design}

A Construção de protótipos e modelos através da modelagem tradicional manual é extrema importância para o Design, pois permite que os profissionais durante as fases de desenvolvimento de um produto consigam materializar e testar uma ideia.

Para Penna (2002) os Protótipos são uma resposta do Designer de acordo com as necessidades da etapa do projeto, podem ser executados com diferentes técnicas e materiais, traduzindo a beleza e dando 'vida' ao projeto bidimensional, ajudando a verificar dimensões, formas, cores, sequência de uma família de produtos e sua aceitação no mercado.

Ao que Kindlein (2006) adiciona que nas diferentes fases do trabalho de concepção de novos produtos é necessário encontrar maneiras para que o produto possa mobilizar o interesse dos Designers sobre os aspectos ligados aos materiais e processos de fabricação, e também mobilizar o interesse dos engenheiros sobre os aspectos ligados ao futuro usuário. Isto ocorre quase sempre por meio da construção de modelos que possam de fato ser testados.

Ao pensar no designer e em toda a equipe de desenvolvimento de produto, Martins (2010) afirma que construir um modelo físico ajuda a captar as corretas intenções e transferi-las para outras formas de representação, assegurando que esse conhecimento possa ser encaminhado para uma definição do produto final.

O conhecimento e experiência dessas técnicas e matérias também são importantes para o estudante e futuro profissional em Design, como Barbosa (2009) atenta para o uso e os benefícios da prototipagem convencional manual nas instituições de ensino de Design, pois elas permitem experimentações plásticas ou processo que amplie o conhecimento e o repertório dos acadêmicos, sendo importantes porque introduzem os profissionais nas tecnologias de construção de objetos.

Assim fica evidente a importância do conhecimento da e experiência das técnicas de modelagem tradicionais e os seus respectivos materiais e que os mesmos estejam inseridos não só nas fases de desenvolvimento de um produto mas também no ensino, contribuindo para o êxito no desenvolvimento dos produtos mais coerentes.

\subsection{Técnicas de Prototipagem tradicional}

Os modelos e protótipos podem ser confeccionados com os mais simples materiais como papel e cola ou argila - como podem ser confeccionados nas mais sofisticadas e complexas máquinas de Prototipagem Rápida- por adição ou remoção de material -, que permitem a confecção de protótipos funcionais.

No entanto, é importante que se diga que, entre o mais simples material e a mais sofisticada máquina de prototipagem, existe uma infinidade de materiais e técnicas, que permitem o mais alto nível de qualidade, tecnologia, sofisticação em cada etapa do desenvolvimento de um produto.

Modelos estes que são quase sempre produzidos manualmente. E que Dorta (2006) apud Martins (2010) vai valorizar ao afirmar que às vantagens das ferramentas tradicionais como artefatos cognitivos do design são imensuráveis, pois segundo o autor, nem os desenhos realizados com o auxílio de mesas digitalizadoras, nem os protótipos mais perfeitos construídos 
a partir de Prototipagem Rápida, partilham das mesmas vantagens dos artefatos cognitivos (desenhos e modelos físicos feitos à mão).

Segundo o autor a nossa percepção depende de todos os sentidos para compreender geometrias tridimensionais. Neste sentido, a capacidade de tocar o objeto e sentir as suas formas através dos materiais pode melhorar a criatividade (DORTA, 2006, p.122-133 apud MARTINS, 2010).

De acordo com Knight (2004) nas representações com meios analógicos, o designer recorre à experiência dos sentidos ao utilizar o corpo para compreender e controlar as ferramentas que usa para representar. Já nas representações digitais, o designer não tem meios para compreender conceitos do mundo real, como a natureza do objeto ou a sua função, limitando-se apenas à capacidade de codificar conceitos geométricos.

Segundo Evans (1992, p.43) a avaliação das relações entre os vários elementos formais é mais eficaz quando realizada em três dimensões através da manipulação de materiais, pois o benefício desta avaliação ocorre por meio da aplicação do seu conhecimento através da utilização das suas ferramentas.

Para Martins (2010) os modelos físicos, quando comparados com os modelos digitais, são sempre volumetrias reais e podem ser manipuladas no mundo real/físico, permitindo um controle direto sobre as formas, os detalhes, as texturas, as proporções sem a intermediação de uma simulação da tridimensionalidade.

Forti (2005) corrobora, pois para ele os modelos e protótipos tridimensionais físicos trazem diversas vantagens para o ambiente de projeto, isso porque anulam o esforço cognitivo de interpretar palavras ou imagens totalmente bidimensionais.

Martins (2010) afirma ainda que o modelo físico apresenta uma imagem palpável do objeto que representa, tendo a função de aproximar designers da experiência real do objeto, para ver, tocar, cheirar e ouvir, em vez da sua visualização através de uma sucessão de perspectivas bidimensionais num monitor, oferecendo indicações precisas de escala, na análise e compreensão do peso, forma, variação de textura, entre outros.

De acordo com Hanington (2006, p. 29) para um bom modelo vender uma ideia a potenciais compradores, os mesmos devem experienciar o objeto na sua plenitude em vez de só tentarem visualizar através de representações gráficas ou de uma descrição verbal do produto. Ao que se pode destacar a dificuldade de alguns possíveis usuários na interpretação de modelos digitais tridimensionais.

Para D'Adderio (2001), os modelos físicos, feitos à mão ou obtidos por impressão 3D, são meios fundamentais para conhecer os artefatos, pois a avaliação de alguns aspectos tridimensionais não poderá ser feita sem a manipulação direta da forma e dos materiais.

Martins (2010) afirma ainda que o modelo físico apresenta uma imagem palpável do objeto que representa, tendo a função de aproximar designers da experiência real do objeto, para ver, tocar, cheirar e ouvir, em vez da sua visualização através de uma sucessão de perspectivas bidimensionais num monitor, oferecendo indicações precisas de escala, na análise e compreensão do peso, forma, variação de textura, entre outros.

De acordo com Hanington (2006, p. 29) para um bom modelo vender uma ideia a potenciais compradores, os mesmos devem experienciar o objeto na sua plenitude em vez de só tentarem visualizar através de representações gráficas ou de uma descrição verbal do produto. Ao que se pode destacar a dificuldade de alguns possíveis usuários na interpretação de modelos digitais tridimensionais.

Para D'Adderio (2001), os modelos físicos, feitos à mão ou obtidos por impressão 3D, são meios fundamentais para conhecer os artefatos, pois a avaliação de alguns aspectos tridimensionais não poderá ser feita sem a manipulação direta da forma e dos materiais. 
Sintetizando, pode-se afirmar que modelos digitais e tradicionais devem coexistir dentro das metodologias de projeto. No entanto, isso deve ocorrer sem que se confunda a função de cada um deles, pois enquanto protótipos palpáveis de fato permitem testes físicos, de interação e que digam respeito à composição formal, modelos digitais - embora alguns programas permitam testes físicos - ainda não permitem testes de uso, apesar de serem mais rapidamente produzidos.

Buscando a compreensão da construção de modelos, a seguir serão classificados os materiais e as técnicas utilizadas na prototipagem tradicional.

\subsection{Classificações das técnicas de prototipagem tradicional}

Relvas (2002) afirma que a construção de modelos e protótipos tem sido usada ao longo dos tempos como forma de criação e desenvolvimento de novos produtos, pois o desenvolvimento de um protótipo não só permite dar forma e dimensão a uma ideia, criando um modelo físico e palpável, como possibilita a detecção de eventuais defeitos antes da fase de produção.

Esse é um dos motivos pelo qual a construção de um protótipo é feita utilizando as mais variadas técnicas e tecnologias que podem ser classificadas como tradicionais quando feitas manualmente e digitais quando tem a participação de algum software e máquinas de Prototipagem Rápida.

Dentro do processo de prototipagem tradicional estão as seguintes técnicas:

\subsubsection{Modelagem Manual}

De acordo com Relvas (2002) esse é um dos processos mais antigos e atualmente tem se voltado uma produção artística, na construção de um modelo único.

Segundo Alves et al. (2001 apud. RELVAS, 2002) este processo requer grande habilidade e destreza do modelador, sendo difícil garantir rigor geométrico e dimensional (figura 01). Assim os modelos podem ser produzidos nos mais variados materiais, ao que se nota a utilização de materiais de fácil manipulação, como a argila, o gesso, a plastilina, o clay, a espumas de poliuretano, a madeira, o papel, as chapas de poliestireno, o PVC, o isopor, massa epóxi, entre outros. 
Figura 01 - Modelagem manual em plastilina

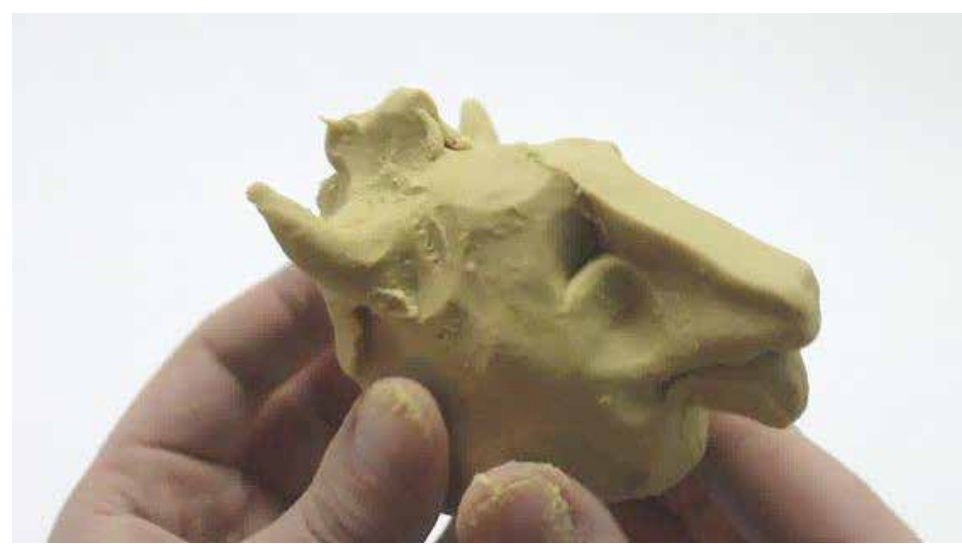

FONTE: http://pad3.whstatic.com/. (2017)

\subsubsection{Maquetismo}

Relvas (2002) afirma que o maquetismo também é uma técnica bastante antiga, sendo geralmente associada à fabricação de modelos reduzidos ou em escala, normalmente de projetos de engenharia, arquitetura e urbanismo (figura 02) ou modelos de grande volumetria como carros, barcos, aeronaves, etc.

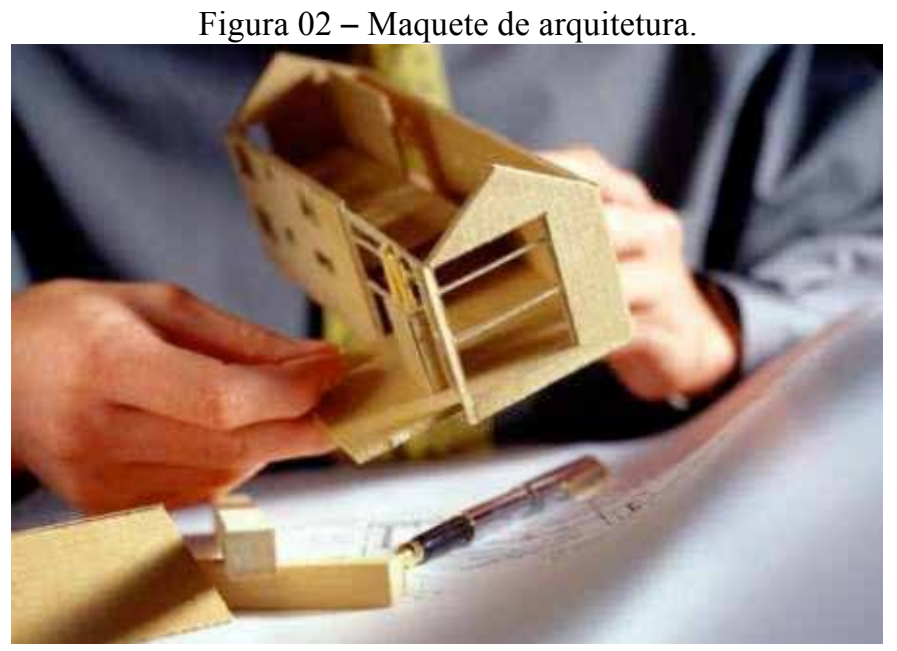

FONTE: http://www.mpsnet.net/loja/det11/se0066/Maquete (2017)

De acordo com Alves et al. (2001 apud. RELVAS, 2002) no maquetismo, o objeto pode anteceder o projeto como forma de ajudar o projetista no desenvolvimento do projeto, onde o mesmo poderá fazer análises e simulações, Ou ainda construir modelos para vender ideias em fases exploratórias, podendo ser utilizados diversos materiais na construção de maquetes como papel cartão, cartolina, gessos, plastilina, fibras, madeiras, plásticos, isopor, chapas de poliestireno, entre outros.

\subsubsection{Construção de Moldes}

Relvas (2002) afirma que, devido às limitações próprias dos processos de prototipagem rápida, por vezes não é possível a obtenção do protótipo diretamente no material do produto 
final. Ainda que o material do protótipo seja o mesmo do produto final pode haver a necessidade de produzir várias unidades, ou mesmo uma pré-série.

Assim, é preciso a construção de moldes para a obtenção de um protótipo em um material que se assemelhe do final ou para a replicação de mais peças, quando for necessário. Este processo permite a produção de diversas peças que podem variar de acordo com o manuseio do molde, aumentando ou diminuindo sua vida útil do molde.

Outra vantagem do uso de moldes é a obtenção de peças ocas com o sistema de rotomoldagem. Na construção desses moldes pode se utilizar silicone, alginato (figura 03), gesso ou cerâmica para moldes de modelo perdido.

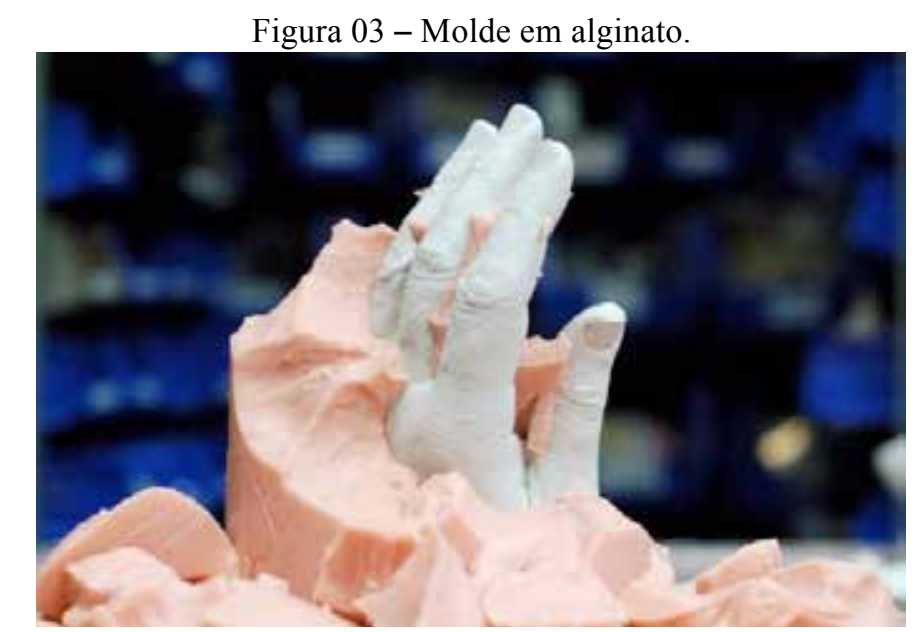

FONTE: http://fabricalo.net/wp-content/uploads/2013/04/alginato (2017)

\section{OBJETIVO}

Este estudo tem como objetivo comparar as diversas técnicas de prototipagem tradicional executadas manualmente, utilizando e classificando as mais variadas técnicas e materiais, levando em consideração critérios como Custo, Tempo de execução e Nível de dificuldade, elegendo para isso um produto (embalagem) que servirá de exemplo a fim de gerar comparações entre os modelos desenvolvidos.

\section{MATERIAIS E MÉTODOS}

Com base nessa importância que os protótipos e suas técnicas de confecção representam para o Design esse trabalho esse trabalho realizou um levantamento das técnicas de prototipagem e materiais que pudessem ser realizadas de forma manual para a construção dos modelos.

\subsection{Objeto de estudo}

Para a realização deste trabalho construíram-se modelos em diferentes técnicas de prototipagem manual, e para que pudessem ser comparados, independente da técnica de produção do mesmo, buscou-se a por um produto que servisse de base.

Assim, buscou-se por um produto de dimensão pequena e cuja forma fosse diferenciada e apresentasse alguma complexidade. Além disso, desejava-se que as questões relacionadas ao Design de produto já estivessem estabelecidas, e para tanto, selecionou-se uma embalagem reconhecida em premiações da área do Design de Produto e do Design de embalagem (Prêmio 
Abre de embalagem, Prêmio Embalagem Marca, Premio brasileiro de embalagem Troféu Roberto Hiraishi, por exemplo), apresentada na figura 04.

Figura 04 - Embalagem de cappuccino.

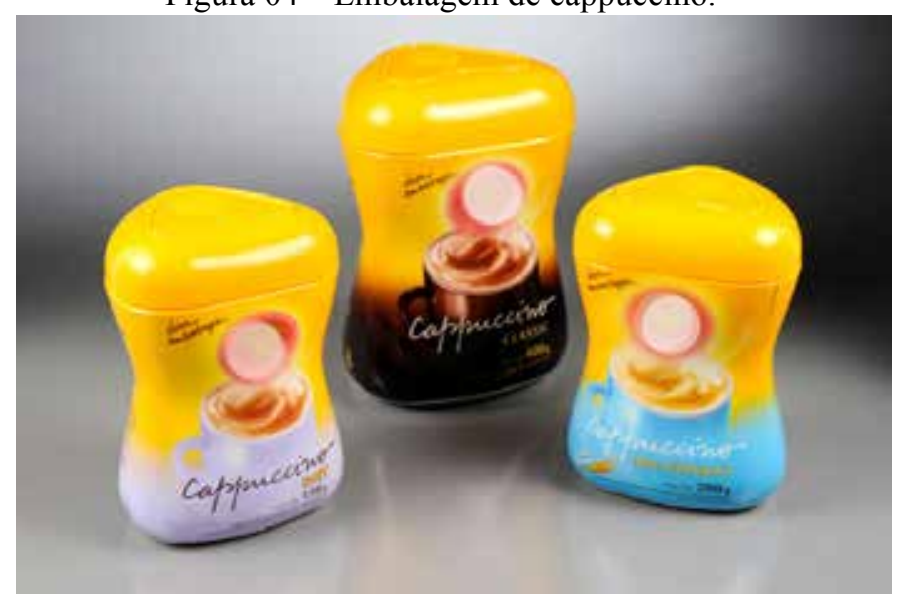

FONTE: http://www.embalagemmarca.com.br. (2017)

\subsection{Confecção dos modelos}

Foram desenvolvidos 12 modelos, em 6 diferentes técnicas que apresentavam predominância manual na sua execução e o uso de 9 tipos diferentes de materiais (Figura 05). Em alguns casos foi utilizado algum maquinário elétrico, mas $80 \%$ da execução foi manual.

Figura 05 - Embalagem de cappuccino.

\begin{tabular}{|c|c|c|}
\hline Modelos & Equipamento/técnica & Material \\
\hline M1 & Papel Machê & Papel / Cola \\
\hline Me & Plano seriado & Papeläo / Cola \\
\hline M3 & Encaixe & MDF / Cola \\
\hline M4 & Usinagem / Modelagem & Espuma PU \\
\hline M5 & Plano Seriado & MDF / Cola \\
\hline Ms & Modelagem & Clay \\
\hline M7 & Usinagem / Modelagem & MDF/Cola \\
\hline Ms & Molde Silicone & Gesso \\
\hline M9 & Molde Silicone & Resina Poliéster \\
\hline M10 & Molde Silicone & Cera \\
\hline A11 & Molde Silicone & Resina PU \\
\hline M12 & Rotomoldagem & Resina PU \\
\hline
\end{tabular}

FONTE: Do Autor. (2017) 
Vale destacar que os modelos foram confeccionados buscando máxima proximidade com o objeto original, principalmente no que diz respeito às dimensões.

\subsubsection{Modelo em Papel.}

Este modelo é um modelo simples, rápido de ser confeccionado, neste caso foi feito a partir de camadas de papel craft e cola (Figura 06).

Figura 06 - Construção do modelo em Papel.

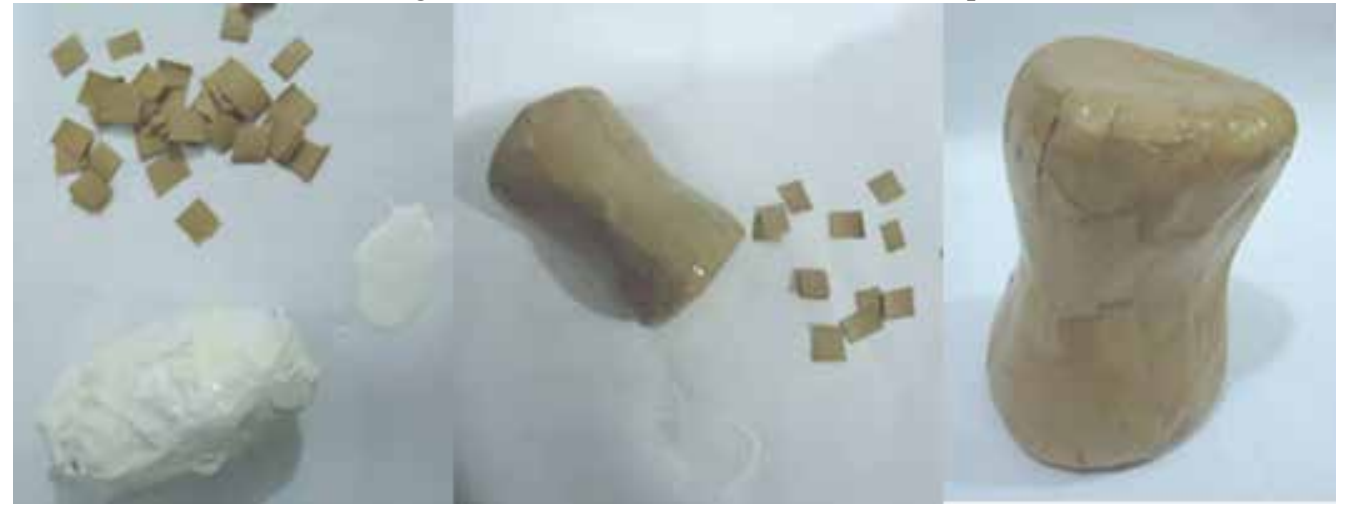

FONTE: Do Autor. (2017)

\subsubsection{Modelo em Madeira (MDF), técnica de modelo fatiado ou placas empilhadas.}

Este modelo caracteriza-se pelo empilhamento das fatias até forma final do objeto, confeccionado a partir de um modelo digital (Figura 07).

Figura 07 - Construção do modelo em Placas empilhadas.

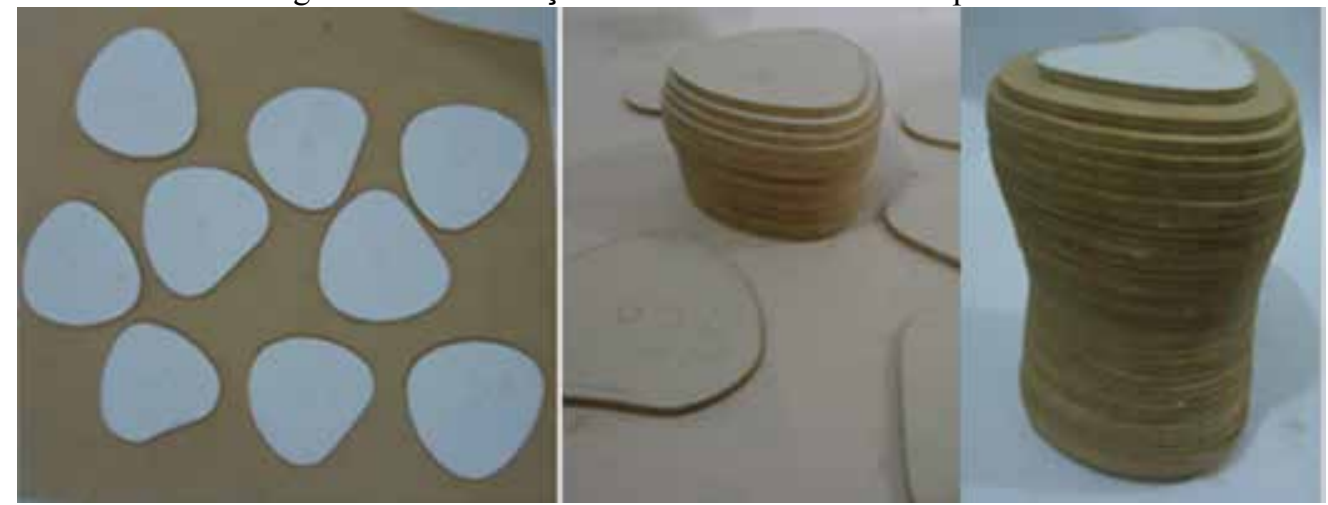

FONTE: Do Autor. (2017)

\subsubsection{Modelo em Madeira (MDF) técnica de encaixe de placas.}

Este modelo caracteriza-se pelo encaixe de diversos plano até forma final do objeto (figura 08), confeccionado a partir de um modelo digital. 
Figura 08 - Construção do modelo em Placas encaixadas.

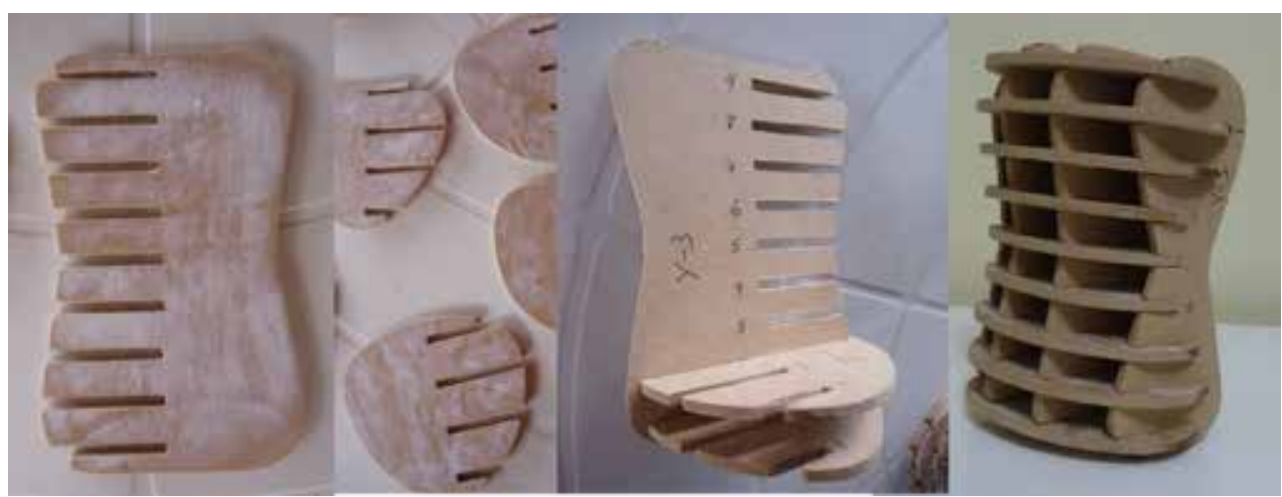

FONTE: Do Autor. (2017)

\subsubsection{Modelo em Clay.}

Modelo confeccionado em clay, que é uma argila a base de óleo, muito maleável e que permite uma plástica incrível possibilitando criação de diversas formas (figura 09).

Figura 09 - Construção do modelo em Clay.

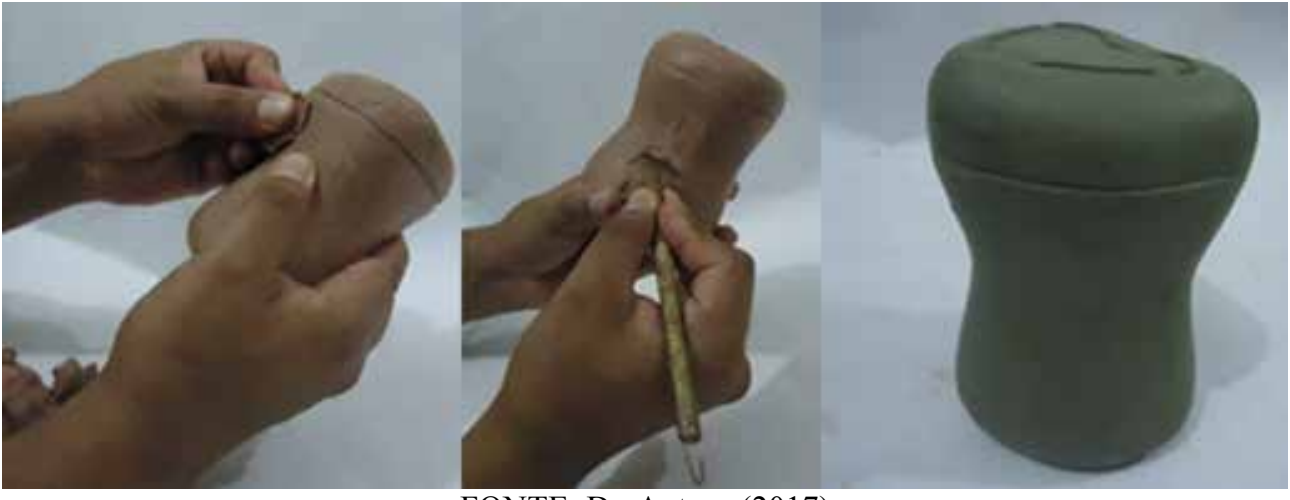

FONTE: Do Autor. (2017)

\subsubsection{Modelo em Madeira (MDF) ou Espuma de Poliuretano(PU) modelagem.}

Modelo confeccionado a partir da usinagem de um bloco de madeira (MDF ou Bloco de Poliuretano, com a ajuda de uma serra fita e disco de lixa (figura 10).

Figura 10 - Construção do modelo em madeira (MDF) usinado.

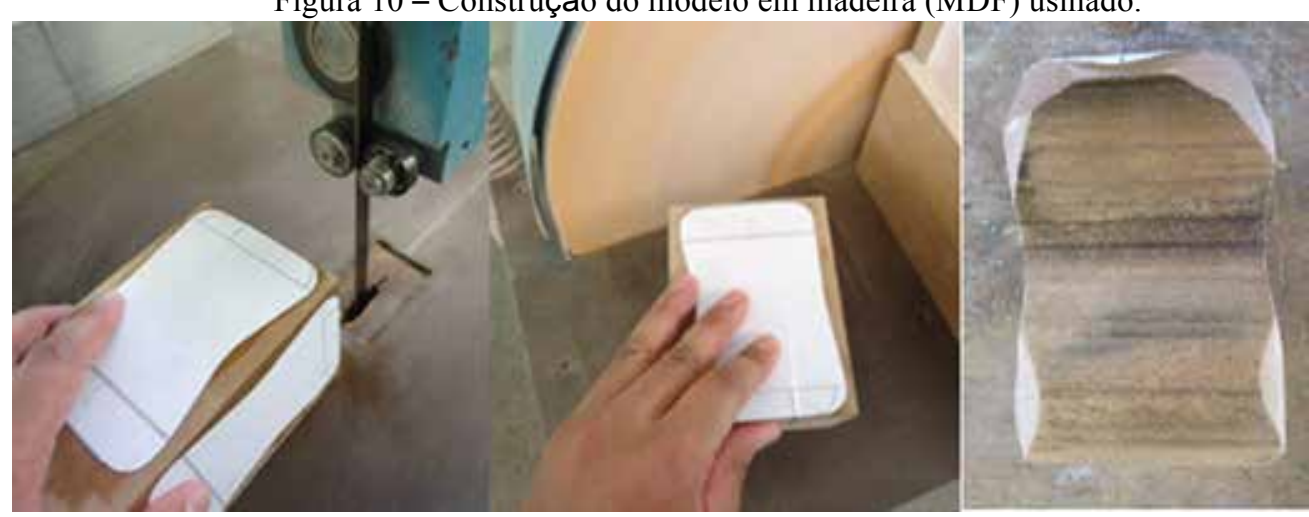

FONTE: Do Autor. (2017)

4.2.6 Molde bipartido com Silicone: utilizando para preenchimento Gesso, Resina de Poliéster, Cera, Resina de Poliuretano. 
Molde de Silicone bipartido (figura 11) utilizado para replicação de peças nos mais diversos materiais como resinas, Gessos, Ceras e até metais fundidos.

Figura 11 - Molde de silicone bipartido.

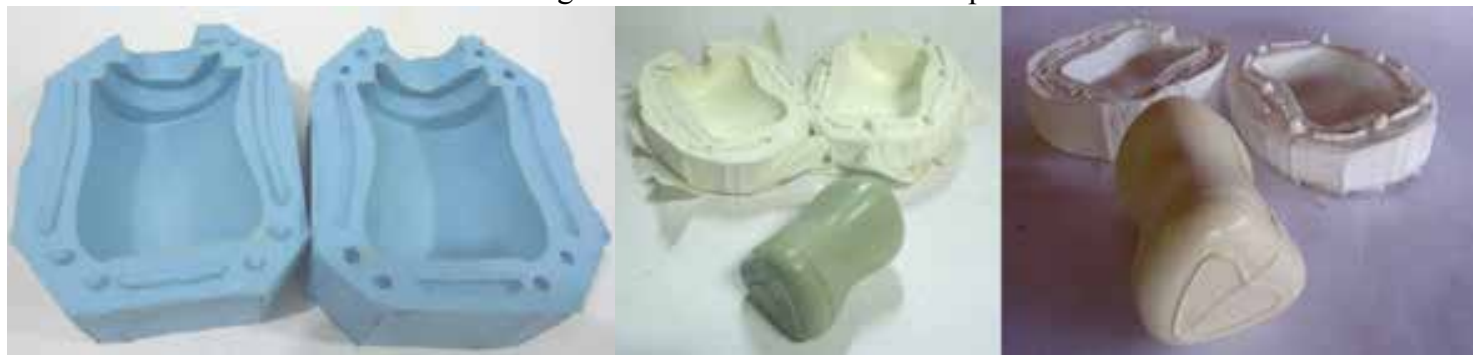

FONTE: Do Autor. (2017)

\subsubsection{Modelo utilizando molde de silicone e resina de Poliuretano: processo de Rotomoldagem Manual.}

Processo de rotomoldagem manual (figura 12) utilizando molde de silicone, esse processo permite a confecção de peças ocas que se aproximam ao máximo do produto original.

Figura 12 - Modelo confeccionado através do processo de Rotomoldagem.

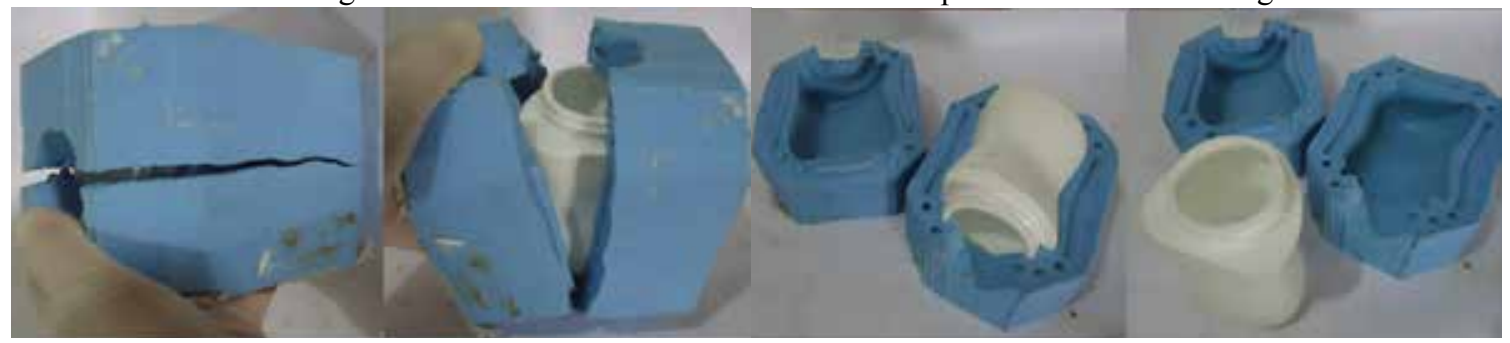

FONTE: Do Autor. (2017)

\subsection{Comparação do modelos}

A fim de permitir que os modelos fossem comparados, pensou-se em parâmetros que pudessem ser medidos e quantificados, a fim de gerar uma reflexão que não fosse uma avaliação subjetiva.

Dessa forma, os modelos foram medidos com ajuda de um Paquímetro Digital de $300 \mathrm{~mm} / 12$ " Absolute da marca Mitutoyo, utilizado para coleta de larguras e comprimentos (Figura 13) e pesados em uma Balança Eletrônica Filizola, modelo MF - 3/1, com peso máximo de três Quilogramas e mínimo de 10 gramas (Figura 14).

Figura 13 - Paquímetro Digital Mitutoyo, utilizado na medição dos modelos.

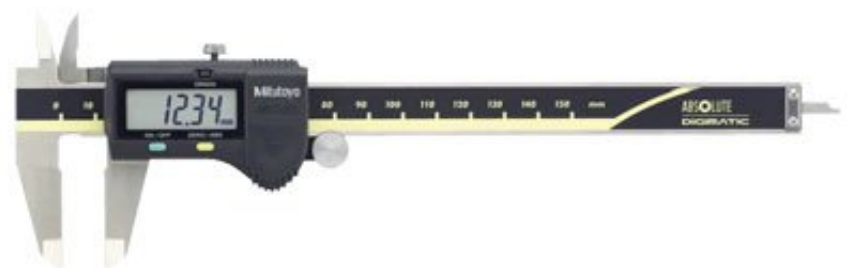

FONTE: Do Autor. (2017) 


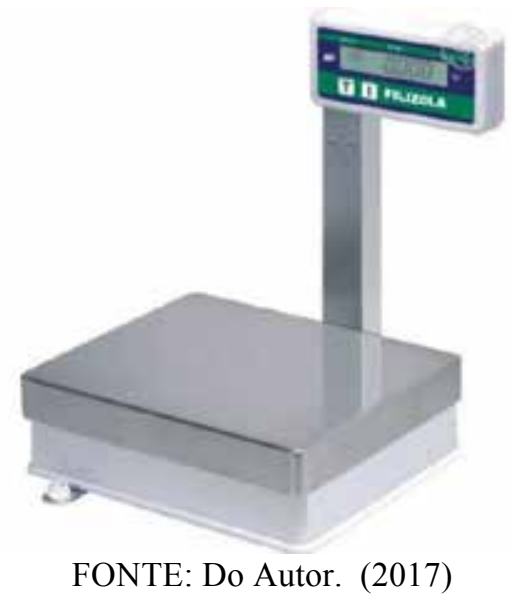

Além disso, todo material utilizado para produção dos modelos foi quantificado quanto a custo e mediu-se o tempo de execução dos mesmos. Gerando-se assim, parâmetros de comparação.

\section{RESULTADOS E DISCUSSÕES}

\subsection{Pesos e dimensões}

Os modelos foram pesados um a um e tabulados para serem comparados ao objeto que serviu de referência para a construção dos mesmos. Em relação ao peso, as técnicas tradicionais manuais mostraram algumas diferenças em relação ao peso da embalagem original, estando esta vazia ou cheia. Ou seja, nenhuma das técnicas conseguiu atingir com exatidão o peso do objeto original (Figura 15).

Figura 15 - Pesos dos modelos.

\begin{tabular}{|c|c|c|c|c|c|c|c|c|c|c|c|c|c|c|}
\hline MODELOS & $\begin{array}{l}\text { Objeto } \\
\text { Original } \\
\text { vazio }\end{array}$ & $\begin{array}{l}\text { Objeto } \\
\text { Original } \\
\text { cheilo }\end{array}$ & M1 & $m=$ & M3 & $m$ & ms & $m$ & Mr & $\mathrm{ms}$ & mo & mid & min & \\
\hline $\begin{array}{c}\text { PESO } \\
\text { (g) }\end{array}$ & 44.5 & 249.5 & 237.0 & 73.0 & 152.5 & 55.5 & 470.0 & 747.0 & 352.0 & 610.5 & 599.5 & 589.0 & 509.0 & 73.5 \\
\hline
\end{tabular}

Destacam-se pela aproximação do peso do objeto original vazio os modelos M2 (Papelão e cola), M4 (Espuma de poliuretano) e M12 (Resina de poliuretano rotomoldada manualmente), respectivamente. Sendo M2 o modelo que mais se aproximou da embalagem original. Outra observação que é feita é em relação a M12 que por ser confeccionado por rotomoldagem manual diferencia-se dos demais por apresentar funcionalidade, pois permite a abertura da tampa.

$\mathrm{Na}$ comparação de peso com objeto original cheio o único modelo que se aproximou foi o M1 (Papel machê), ao que se pode dizer que, para o critério peso, em algumas avaliações de modelos e protótipos, onde esse critério é bastante importante, haveria a necessidade de controlar o material nas técnicas apresentadas neste trabalho, ou ainda descobrir novas possibilidades.

Os modelos também foram medidos com um paquímetro digital a fim de se obter precisão em relação às dimensões. E observou-se que todos os modelos tiveram uma grande 
aproximação com o objeto original, apresentando diferenças de 3 a $4 \mathrm{~mm}$ para mais ou para menos (Figura 16).

Figura 16 - Dimensões dos modelos.

\begin{tabular}{|c|c|c|c|c|c|c|c|c|c|c|c|c|c|c|}
\hline MODELOS & $\begin{array}{l}\text { Objeto } \\
\text { Original } \\
\text { vazio }\end{array}$ & $\begin{array}{l}\text { Objeto } \\
\text { Original } \\
\text { cheio }\end{array}$ & $m$ & $M 2$ & $\mathrm{~m}$ & $\mathrm{~m}_{4}$ & 105 & 105 & $M$ & 48 & $M$ & M10 & & M12 \\
\hline $\begin{array}{l}\text { DIMENSÃO } \\
(\mathrm{mm})\end{array}$ & 119.16 & 119.16 & 116.0 & 116,0 & 118,2 & 120,7 & 124,9 & 117,0 & 121,3 & 117,0 & 111,3 & 118,7 & 114,2 & 116,5 \\
\hline
\end{tabular}

FONTE: Do Autor. (2017)

Podendo-se afirmar que quanto ao critério dimensão todos os modelos apresentaram-se como satisfatório, o que seria de grande importância para análises dentro do processo de desenvolvimento de um produto, por exemplo, para testes de uso e de pega.

\subsection{Custos}

Os modelos foram construídos com diversos materiais e técnicas, que iam desde materiais básicos até os mais sofisticados possibilitando a análise de custo de cada modelo, quantificando valores de matéria prima, tecnologias, mão de obra e tempo de execução.

Destaca-se que a análise foi realizada a partir do custo dos materiais e tecnologias no mercado e a mão de obra foi quantificada com uma média feita entre profissionais do mercado que constroem modelos de maneira tradicional e profissionais de modelagem virtual (Figura 17).

Em relação ao custo, as técnicas tradicionais manuais apresentaram diversos valores, notando-se o baixo custo do modelo M1 (Papel Machê), pois esse modelo consiste apenas de papel e cola, material esse que além de ser fácil de encontrar tem um baixo custo, tornando mais viável a confecção do modelo. Além disso, este modelo (M1), em relação aos demais, apresenta um tempo muito menor de confecção.

Os modelos M2 (Papelão e Cola), M3 (Encaixe MDF / Cola), M4 (Espuma de Poliuretano), M5 (Fatias MDF / Cola) e M7 (Usinagem MDF / Cola) apresentam os maiores valores por conta do material e do valor cotado referente ao trabalho de um profissional, uma vez que estes modelos necessitam de uma modelagem 3D (virtual) a fim de se obter as medidas exatas. Este modelo 3D, no caso de M2, M3 e M5, auxilia na construção das fatias e encaixes.

Os M8 (Gesso), M9 (Resina de Poliéster), M10 (Cera), M11 (Resina de Poliuretano), M12 (Resina de Poliuretano Rotomoldada) também apresentam um custo mais elevado, pois necessita de um molde que permita a confecção do modelo, no caso, molde de silicone. Esse custo está ligado também à mão de obra do profissional de modelagem que vai executar o trabalho.

Assim, nota-se que, com exceção de M1, o custo da mão de obra, o molde e o tempo de execução dos demais modelos se aproximam (Figura 17). 
Comparação de técnicas de prototipagem tradicional manual

e sua importância para o design

Figura 17 - Comparação de custos e tempo de execução dos modelos..

\begin{tabular}{|c|c|c|c|c|}
\hline Modelos & Equipamento/técnica & Material & $\begin{array}{l}\text { Custo final } \\
\text { do modelo ( } R \$)\end{array}$ & $\begin{array}{c}\text { Tempo } \\
\text { (h) }\end{array}$ \\
\hline Mi & Papel Mache & Papel / Cola & 21,00 & 10 \\
\hline Mo & Plano seriado & Papelão / Cola & 830,00 & 140 \\
\hline MB & Encaixe & MDF / Cola & 840,00 & 140 \\
\hline M4 & Modelagem / Usinagem & Espuma PU & 850,00 & 140 \\
\hline M5 & Plano Seriado & MDF / Cola & 840,00 & 140 \\
\hline Ms & Modelagem & Clay & 750,00 & 144 \\
\hline Mr & Modelagem / Usinagem & MDF / Cola & 840,00 & 127 \\
\hline Mes & Molde Silicone & Gesso & 688,00 & 185 \\
\hline M9 & Molde Silicone & Resina Pliéster & 727,00 & 180 \\
\hline M10 & Molde Silicone & Cera & 730,00 & 172 \\
\hline & Molde Silicone & Resina de Poliuretano & 810,00 & 168 \\
\hline M12 & RotoMoldagem & Resina de Poliuretano & 810,00 & 168 \\
\hline
\end{tabular}

FONTE: Do Autor. (2017)

\section{CONCLUSÃO}

Esse estudo apresenta a construção de diversos modelos nos mais variados materiais, quantificando os mesmos e evidenciando a técnica, o tempo e o custo. Permitindo assim refletir sobre a relevância que cada modelo pode ter dentro das etapas de desenvolvimento de produto.

Reflete-se, por exemplo, que técnicas com baixo custo e com menor tempo de execução, mas que possuem uma dimensão aproximada como o modelo em Papel Machê, pode ser utilizado nas fases iniciais do projeto de desenvolvimento de um produto. Pois o custo de um protótipo nesta fase não deve ser muito alto, uma vez que ocorrem ainda muitas mudanças no projeto.

Outra reflexão importante é quanto ao alcance da prototipagem tradicional manual quando se tem domínio de materiais e técnicas avançadas. Como é o caso do modelo em Resina de Poliuretano, que por ter um tempo de cura rápido permite a Rotomoldagem Manual, possibilitando a confecção de um modelo oco e com tampa, cuja interação se aproxima muito do objeto original. Assim, mesmo um modelo confeccionado manualmente permite que se realize testes de funcionalidade, como de pega e torque para abria a tampa.

Para futuros estudos outras técnicas e materiais poderiam ser empregadas e novos testes poderiam ser realizados com os modelos a fim de se estabelecer outras diretrizes, principalmente no que tange testar a aplicação destes modelos no desenvolvimento de projetos.

Por fim, destaca-se a importância do estudante de Design e, consequentemente, do profissional conhecer e saber utilizar ao longo de um projeto diferentes técnicas e materiais que possam auxiliar na construção de protótipos, com maior ou menor fidelidade, levando em consideração custos, tempo e exequibilidade. 


\section{Referências}

ALCOFORADO, M. G. Metodologia de Design Mediada por protótipos [Tese de Doutorado] Bauru: Unesp, 2014, 460 p.

BARBOSA, R. T. Design \& Prototipagem: Conhecimento e uso da prototipagem Rápida no Design Brasileiro. [Dissertação de Mestrado] Bauru, UNESP, 2009, 198p.

BAXTER, M. Projeto de Produto: Guia prático para o desenvolvimento de novos produtos. São Paulo. Editora Edgard Blücher Ltda. 1998.

CARDOSO, Rafael. Uma introdução à história do Design.3. ed.São Paulo:Edgard Blücher, 2008.

CHRISSIS, M.B. et al. Guidelines for Process Integration and Product Improvement, Addison-Wesley, 2003.

D'ADDERIO, L., Crafting the Virtual Prototype: How Firms Integrate Knowledge and Capabilities Across Organisational Boundaries, Research Policy, Vol. 30, pp.1409-24. 2001.

DORTA, T., Vers la maîtrise du virtuel à travers le réel: un nouvel usage de l'informatique en design, Université de Montreal, 2006, pp.131-138.

EVANS, M., Model or prototype which, when and why? IDATER, Conference, Loughborough University, 1992, pp.42-46

FORTI, F. S. A. Uma Avaliação do ensino da Prototipagem Virtual nas Graduações de Design de Produto do Estado do Rio de Janeiro. 2005, 105p. Dissertação (Mestrado], COPPE, Universidade Federal do rio de Janeiro.

HANINGTON, B. M., Interface in form: paper and product prototyping for feedback and fun, Volume 13, Issue 1, The art of prototyping, 2006, pp.28-30.

KNIGHT, T. Interaction in Visual Design Computing, Massachusetts Institute of Technology, Cambridge, Massachusetts, EUA, 2004 p.1-31.

KINDLEIN, W. J. A importância do Binômio Design e Engenharia como Catalisador de Inovação. $6^{\circ}$ Congresso Brasileiro de Pesquisa e Desenvolvimento em Design, 2004, FAAP, São Paulo. In: Anais $6^{\circ}$ Congresso Brasileiro de Pesquisa e Desenvolvimento em Design, FAAP, São Paulo, 2004.

MARTINS, A. F. P. Da maqueta para o desenho: meios de representação tridimensional no design de artefactos, 2010, 149p. Dissertação (Mestrado) Aveiro: Universidade de Aveiro. 
PENNA, E. Modelagem, modelos em design, São Paulo. Catálise, 2002.

RELVAS, C. A. M.; Processos de prototipagem rápida no fabrico de modelos de geometria complexa: Estudo realizado sobre modelo anatômico da mão. 2002, 121p Dissertação (Mestrado) Faculdade de Engenharia da Universidade do Porto, Porto.

SANTOS, J. R. L. Breve histórico do uso de modelos 3D físicos no desenvolvimento de projetos. $7^{\circ}$ Congresso Brasileiro de Pesquisa e Desenvolvimento em Design, 2006 UFPR, Curitiba, In: Anais $7^{\circ}$ Congresso Brasileiro de Pesquisa e Desenvolvimento em Design, 2006 UFPR, Curitiba, 2006.

ULRICH, K.T.; EPPINGER, S. D., Product design and development,-3rd ed. McGrawHill/Irwin, 1995.

VOLPATO, N.; FERREIRA, C. V.; SANTOS, J. R. L. Integração da prototipagem rápida com o processo de desenvolvimento de produto. In: Prototipagem Rápida: Tecnologias e aplicações, São Paulo: Edgar Blücher, 2007.

Agradecimentos: Este trabalho foi desenvolvido com o apoio da CAPES. 